\title{
THERMODYNAMIC PERFORMANCE ANALYSIS OF GAS LIQUEFACTION CYCLES FOR CRYOGENIC APPLICATIONS
}

\author{
C. Yilmaz ${ }^{1,}$, T. H. Cetin², B. Ozturkmen², M. Kanoglu²
}

\begin{abstract}
In this paper presents an analysis of the thermodynamic cycles the most commonly used for the liquefaction of gases in order to evaluate and compare their performance under given working conditions and system component efficiencies. The cycles considered are simple Linde-Hampson cycle, precooled LindeHampson cycle, Claude cycle, and Kapitza cycle. First and second law relations are investigated for each cycle and performance parameters are evaluated. Thermodynamically performances criteria are compared of cycles with respect to the each other. Cycles are model in the computer environment and analyzed with Engineering Equation Solver (EES) software program. Cycles of the liquefaction fractions, coefficient of performances and second law of efficiencies are calculated for the liquefaction of different gases. Second law efficiencies are calculated as $13.4 \%, 21.8 \%, 62.9 \%$, and $77.2 \%$ for simple Linde-Hampson cycle, pre-cooled Linde-Hampson cycle, Claude cycle, and Kapitza cycle, respectively. Claude and Kapitza cycles give better performance but simple and precooled Linde-Hampson cycle has the advantages of the simplicity of their setup.
\end{abstract}

Keywords: Cryogenic Cycles, Linde-Hampson, Claude, Kapitza, J-T Expansion, Thermodynamic Analysis

\section{INTRODUCTION}

Liquefaction is a key branch of cryogenics and has wide application areas including producing commercial liquid gases and cryogenic engineering applications. The main scope of cryogenic engineering is the design, development and improvement of low temperature systems and components. In today's world, cryogenics and low-temperature refrigeration are taking on increasingly significant roles. From applications in the food industry, energy and medical technologies to transportation and the space shuttle, requirements exist for cryogenic liquids to be stored and transferred.

Cryogenics is the science that involves study of very low temperatures. Low temperatures usually obtained by using liquefied gases such as liquid nitrogen or liquid helium. Therefore, liquefaction of gases is an important area for cryogenic technologies. There are three main methods for producing refrigeration; liquid expansion, Joule-Thomson expansion and expansion engine. Liquid expansion cycles are conventional refrigeration cycles and suitable for obtaining temperatures around $-70^{\circ} \mathrm{C}$. Kanoglu [1] performed an exergy analysis of a cascade refrigeration system for producing LNG.

The second method is the Joule-Thomson expansion and utilizes the Joule-Thomson effect to produce low temperatures. Gas is compressed to a high pressure, cooled in the counter-current heat exchanger, and expanded through a J-T valve. In 1895, Carl von Linde and William Hampson developed a cycle for the liquefaction of air [2]. However, in 1966 Andrew Barron found that the Linde and Hampson cycle could also be used to liquefy hydrogen by incorporating a precooling process using liquid nitrogen. Similarly, the Claude cycle, invented in 1902 by Georges Claude, was developed to liquefy air but it can also be used to liquefy hydrogen. Using liquid nitrogen for precooling improves the cycle efficiency compared to a pre-cooled LindeHampson cycle [3].

Thomas et al. [4] presented, with the help of a commercial process simulator Aspen HYSYS, the exergy analysis of a helium liquefaction system based on modified Claude cycle. Atrey [5] presented a cycle simulation for the Collins helium liquefaction cycle with six heat exchangers and two reciprocating expanders. It highlights the concept of an optimum mass flow rate through expanders for the liquefier. Wang et al. [6] presented a thermodynamic review on cryogenic refrigeration cycles for the liquefaction process of natural gas. The main

This paper was recommended for publication in revised form by Regional Editor Tolga Taner

${ }^{1}$ Department of Mechanical Engineering, Afyon Kocatepe University, Afyonkarahisar, Turkey

${ }^{2}$ Department of Mechanical Engineering, University of Gaziantep, Gaziantep, Turkey

*E-mail address: ceyhunyilmaz@aku.edu.tr

Orcid id: 0000-0002-8827-692X, 0000-0002-6634-9438, 0000-0003-0314-837X, 0000-0002-6042-0758

Manuscript Received 24 July 2017, Accepted 8 August 2017 
concept of this study is to search the thermodynamic analysis of different cycles and provide a theoretical basis for selecting a cycle in accordance with different design conditions. Mehrpooya and Ansarinasab [7] considered a single mixed refrigerant Linde and Air Products liquefaction system. A thermoeconomic model based on energy and exergy analyses and an economic model according to the total revenue requirement are developed. Minimizing the unit cost of the refrigeration effect as a product of liquefaction plant is performed using the optimum working conditions. Bisht [8] performed a thermodynamic analysis of a nitrogen liquefaction system based on Kapitza cycle which is a modified Claude cycle.

Fundamentals and thermodynamic analysis of liquefaction cycles are given in Barron [9] and Timmerhaus and Flynn [10]. Maytal [11] optimized simple Linde-Hampson cycle and determined optimum flow rates of cryocoolers sharing same size recuperator in order to maximize liquid production. Nandi and Sarangi [12] discussed performance of several cycles for hydrogen liquefaction. Hilal [13] optimized Claude cycle for helium liquefiers. Kanoglu et al. [14] performed exergy analysis and developed an expression for the minimum work requirement with the help of a Carnot refrigerator.

Rashidi et al. [15] analyzed the ejector refrigeration cycle using the artificial neural network. In this study, they described the results of the ejector refrigeration cycle using R600 as a working fluid. In this study, they are used EES software for calculating the refrigerant fluid different thermodynamic properties. In the other paper [16], they proposed the thermodynamic performances of a thermal system which combines an organic Rankine cycle and an ejector refrigeration cycle. The performance of different refrigeration working fluids is investigated using classical and finite-size thermodynamics for a case for which the power to refrigeration ratio.

Most conventional cryogenic systems operate with pure fluids, the major exception being natural gas liquefiers that use mixed refrigerant processes. Previous studies on the liquefaction systems have primarily concentrated on performance assessment of a single conventional storage system for a special work. There has also been some work on performance analyses and comparisons of the different liquefaction cycles. Hundreds of patents exist on different aspects of system processes for the liquefaction of natural gas and the composition of mixtures for Linde-Hampson and other cycles. However, it is difficult to piece together the existing information to choose an appropriate process and an optimum composition for a given application.

This study presents an analysis of the thermodynamic cycles commonly used for the liquefaction of gases in order to evaluate and compare their performance under given working conditions and system component efficiencies. The cycles considered are simple Linde-Hampson cycle, precooled Linde-Hampson cycle, Claude cycle, and Kapitza cycle. The main objectives of the study are as follows: (i) First and second laws of thermodynamic relations are developed for each cycle. (ii) Liquefaction cycles performance parameters are evaluated. (iii) Liquefaction fractions, coefficient of performances COP and second law of efficiencies $\eta_{\mathrm{II}}$ are calculated for the liquefaction of different gases. (iv) Effect of inlet gas temperature on the liquefaction fraction, net work input, and second law efficiencies are investigated.

Also, the novelty of this study is due to the configuration of liquefaction system consisting of the integrated part and heat exchangers unit as well as thermodynamic analysis based working conditions of the overall system. Thermodynamic analysis of the liquefaction system cycles are performed and simulated in EES software program and the analysis are performed using the program. Demonstrates thermodynamic analysis of the cycles that results of the cycles analyses for the gas liquefaction, including estimates of liquefied mass rates are presented. The effects of the gas inlet temperature on the liquefaction fraction, unit work requirement, and the efficiencies are investigated and evaluated with the figures. As a result of this study, it is possible to use the gas liquefaction cycles for liquid mass production and storages with the best working conditions and at optimum operating conditions. Parametric studies are performed at varying inlet gas temperatures while optimum operating conditions that minimize the unit gas liquefaction work are obtained in optimization studies.

\section{THERMODYNAMIC PERFORMANCE ANALYSIS OF CYCLES}

An important parameter to be analyzed in any gas liquefaction system is thermodynamic efficiency, since it directly affects liquefied mass fraction of the gas. It is advantageous to know effects of different parameters on the efficiency, so that optimum parameters that result in the best working conditions can be selected. There are four basic components in any gas liquefaction cycle. These are compressors, expanders, heat exchangers, and Joule-Thomson (J-T) valves. The parameters that will be considered for cycle performance analysis are (i) feed gas compressor discharge pressure, (ii) temperature difference between hot and cold flows, 
(iii) lowest cooling temperature, (iv) number of the heat exchangers, and (v) number of expanders. Following assumptions are made in order to simplify the analysis. (i) Pressure drop through the cycle is negligible. (ii) Compressor's isothermal efficiency is $70 \%$. (iii) Isentropic efficiency of the expander is $80 \%$. (iv) Heat losses to the surroundings are negligible.

There are three important parameters for the performance of the liquefaction cycles: work required per unit mass of gas compressed $\frac{-\dot{W}}{\dot{m}}$, work required per unit mass of gas liquefied $\frac{-\dot{W}}{\dot{m}_{f}}$, and fraction of the gas that is liquefied $y=\frac{\dot{m}_{f}}{\dot{m}}$. In any liquefaction cycle, we want to minimize the work requirements and maximize the liquefied gas fraction.

\section{Simple Linde Hampson cycle}

Simple Linde-Hampson cycle has the simplest setup among all liquefaction cycles, but besides its simplicity simple Linde-Hampson cycle can liquefy most of permanent gases except hydrogen and helium. Linde-Hampson cycle consist of a compressor, a heat exchanger, J-T valve and liquid reservoir. At state 1, uncondensed portion of gas and make-up gas is mixed and compressed isothermally to high pressures at the state 2. The high pressure gas is cooled in heat exchanger by uncondensed portion of gas and at state 3 , and the gas is throttled in J-T valve. The liquid portion is collected as desired product. The gas portion is send back to the cycle to cool high pressure gas, and the cycle is repeated. The schematic representation of the simple Linde-Hampson cycle and temperature entropy (T-s) diagram of the cycle are shown in Figs. 1 and 2.

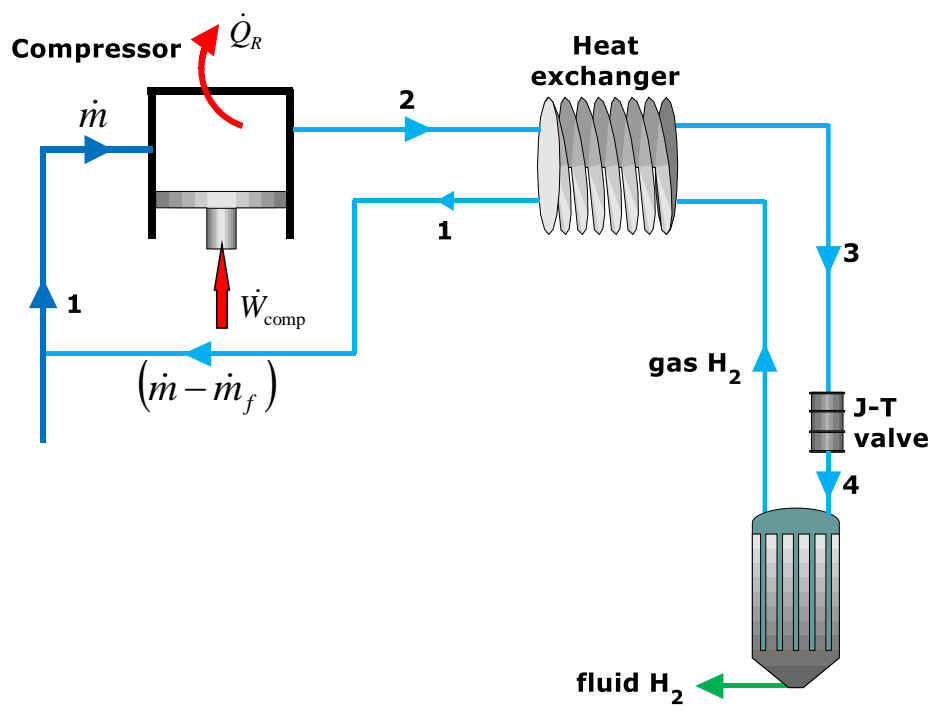

Figure 1. Schematic diagram for a simple Linde-Hampson cycle.

The refrigeration effect per unit mass of liquefaction can be defined as the heat removed from inlet of the compressor state 1 and turn into liquid state. Heat transfer can be expressed as

$$
q_{l}=h_{1}-h_{6}=h_{1}-h_{f}
$$

where $h_{\mathrm{f}}$ is the enthalpy of saturated liquid. From energy balance of the cycle, heat transfer per unit mass of gas can be expressed as in same manner

$$
q_{l}=h_{1}-h_{2}
$$




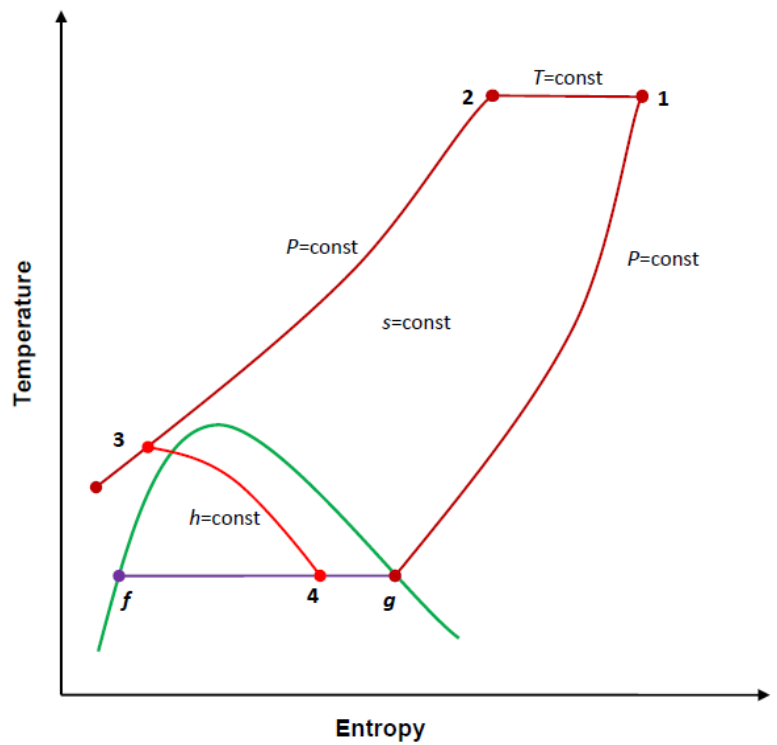

Figure 2. Temperature-entropy $(T-s)$ diagram for a simple Linde-Hampson cycle.

The ratio of Eq. 2 to Eq. 1 is the fraction of liquefied gas in the cycle

$$
y=\frac{h_{1}-h_{2}}{h_{1}-h_{f}}
$$

From Eq. 3, the amount of gas liquefied in the cycle depends on the pressure and temperatures in the ambient condition. Compressor outlet pressure $P_{2}$ is an important parameter for the performance of the cycle.

The energy balance for heat exchanger can be written as

$$
\begin{aligned}
& h_{3}=h_{2}-x\left(h_{1}-h_{g}\right) \\
& h_{1}=h_{g}+\varepsilon\left(h_{1}^{\prime}-h_{g}\right)
\end{aligned}
$$

where $h_{\mathrm{g}}$ is the enthalpy of the saturated vapor and $x$ is quality of state 4. $x$ also can be written as

$$
x=1-y
$$

The energy balance for compressor can be written as

$$
\begin{gathered}
w_{i n}=h_{2}-h_{1}-T_{1}\left(s_{2}-s_{1}\right) \\
h_{2}=h_{1}-\eta\left(h_{1}-h_{2}^{\prime}\right)
\end{gathered}
$$

Joule-Thomson throttling process is isenthalpic so we can write energy balance as

$$
h_{3} \cong h_{4}
$$

The coefficient of performance of this cycle given by

$$
\mathrm{COP}_{\mathrm{act}}=\frac{q_{l}}{w_{\mathrm{in}}}=\frac{h_{1}-h_{2}}{h_{2}-h_{1}-T_{1}\left(s_{2}-s_{1}\right)}
$$


Reversible work provides useful data for comparison between minimum work requirement for liquefaction and actual work requirement. By using second law of thermodynamics, we can develop relations between actual work and reversible work for liquefaction processes.

$$
w_{\text {act }}=w_{\text {rev }}+T_{0} s_{\text {gen }}
$$

The reversible work for the simple Linde-Hampson cycle can be expressed by the exergy difference between state 1 and 6 as

$$
w_{\text {rev }}=e x_{6}-e x_{1}=h_{6}-h_{1}-T_{1}\left(s_{6}-s_{1}\right)
$$

The second law of efficiency can be defined as

$$
\eta_{I I}=\frac{w_{\text {rev }}}{w_{\text {act }}}=\frac{h_{6}-h_{1}-T_{1}\left(s_{6}-s_{1}\right)}{\left(\frac{1}{y}\right)\left[h_{2}-h_{1}-T_{1}\left(s_{2}-s_{1}\right)\right]}
$$

We assume that heat exchanger has an effectiveness of $100 \%$. The J-T valve is isenthalpic, and it's assumed that there is no heat leakage and pressure drop in the cycle. Taking inlet state of compressor to be $25^{\circ} \mathrm{C}$ and $1 \mathrm{~atm}$ and outlet pressure to be $200 \mathrm{~atm}$, we obtain various performance parameters for air, nitrogen, oxygen, argon, methane, and fluorine. They are given in Table 1.

Table 1. Performance parameters of various fluids for a simple Linde-Hampson cycle.

\begin{tabular}{|l|l|l|l|l|l|l|}
\hline Gas & $y$ & $\begin{array}{l}w_{\text {in }} \\
(\mathrm{kJ} / \mathrm{kg})\end{array}$ & $\begin{array}{l}w_{\text {rev }} \\
(\mathrm{kJ} / \mathrm{kg})\end{array}$ & $\mathrm{COP}_{\text {act }}$ & $\mathrm{COP}_{\text {rev }}$ & $\eta_{\mathrm{II}}$ \\
\hline Air & 0.0828 & 5485 & 733.2 & 0.07741 & 0.5791 & 0.1337 \\
\hline Nitrogen & 0.07551 & 6207 & 762.1 & 0.06949 & 0.566 & 0.1228 \\
\hline Oxygen & 0.1071 & 3758 & 629.4 & 0.1076 & 0.6426 & 0.1675 \\
\hline Fluorine & 0.0763 & 4460 & 564.5 & 0.07702 & 0.6086 & 0.1266 \\
\hline Argon & 0.1152 & 2801 & 492.6 & 0.1003 & 0.57 & 0.1759 \\
\hline Methane & 0.1987 & 3892 & 1081 & 0.2338 & 0.8421 & 0.2777 \\
\hline
\end{tabular}

\section{Precooled Linde-Hampson cycle}

The simple Linde-Hampson cycle is simple, it can liquefy many gases, but it is inefficient. The cycle requires high work input per unit liquid yield. There are several methods for improving performance of the cycle. Precooled Linde-Hampson cycle improve the performance of the simple Linde-Hampson cycle by decreasing temperature of the gas entering the main heat exchanger. The temperature lower than ambient is provided by auxiliary refrigeration cycle using a fluid such as carbon dioxide, ammonia, or a freon compound used to cool the main gas stream. The schematic representation and $T-s$ diagram of the Precooled Linde-Hampson cycle is shown in Figs. 3 and 4, respectively.

Thermodynamic analysis of precooled Linde-Hampson cycle can be done in similar manner as simple Linde-Hampson cycle with some modifications. In the first heat exchanger, for $100 \%$ effectiveness, $T_{3}$ and $T_{6}$ are the same and cannot be lower than the boiling point of the auxiliary refrigerant. Refrigeration effect per unit gas can be written as

$$
q_{l}=h_{1}-h_{2}+r\left(h_{a}-h_{b}\right)
$$




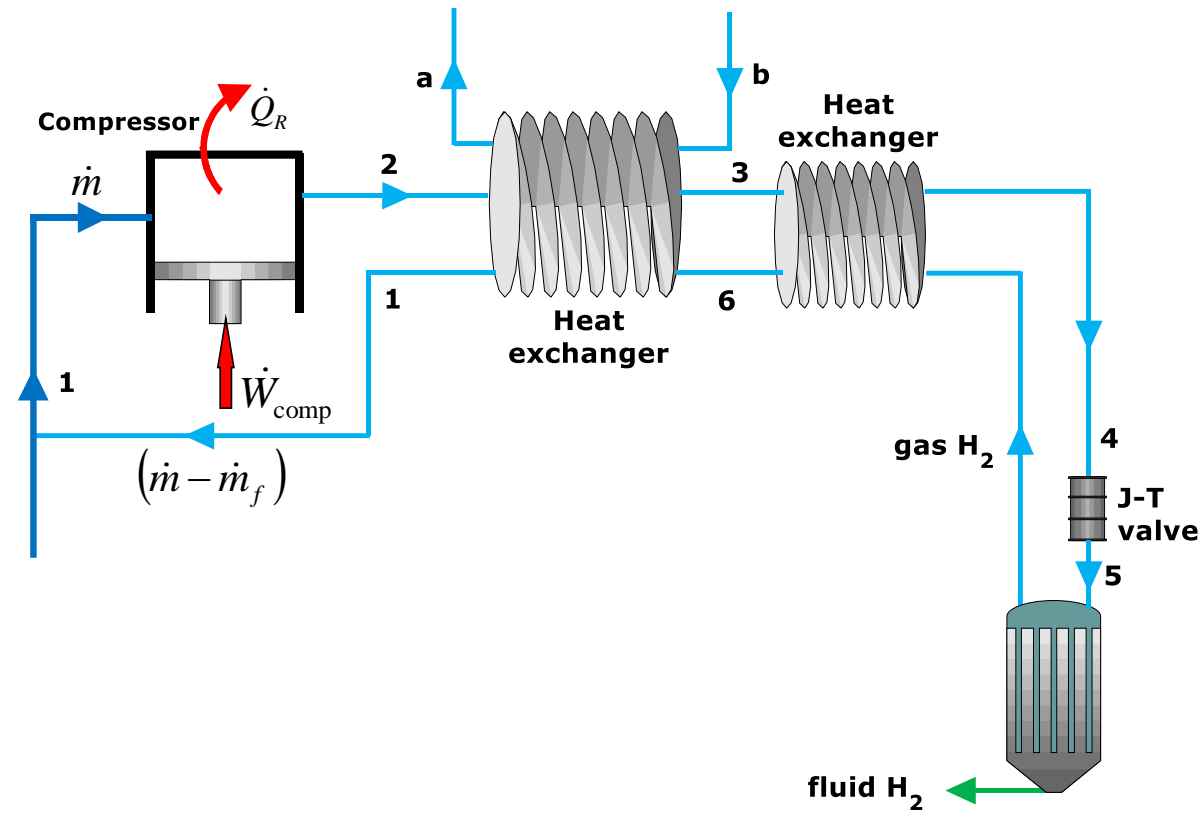

Figure 3. Schematic representation of a precooled Linde-Hampson cycle.

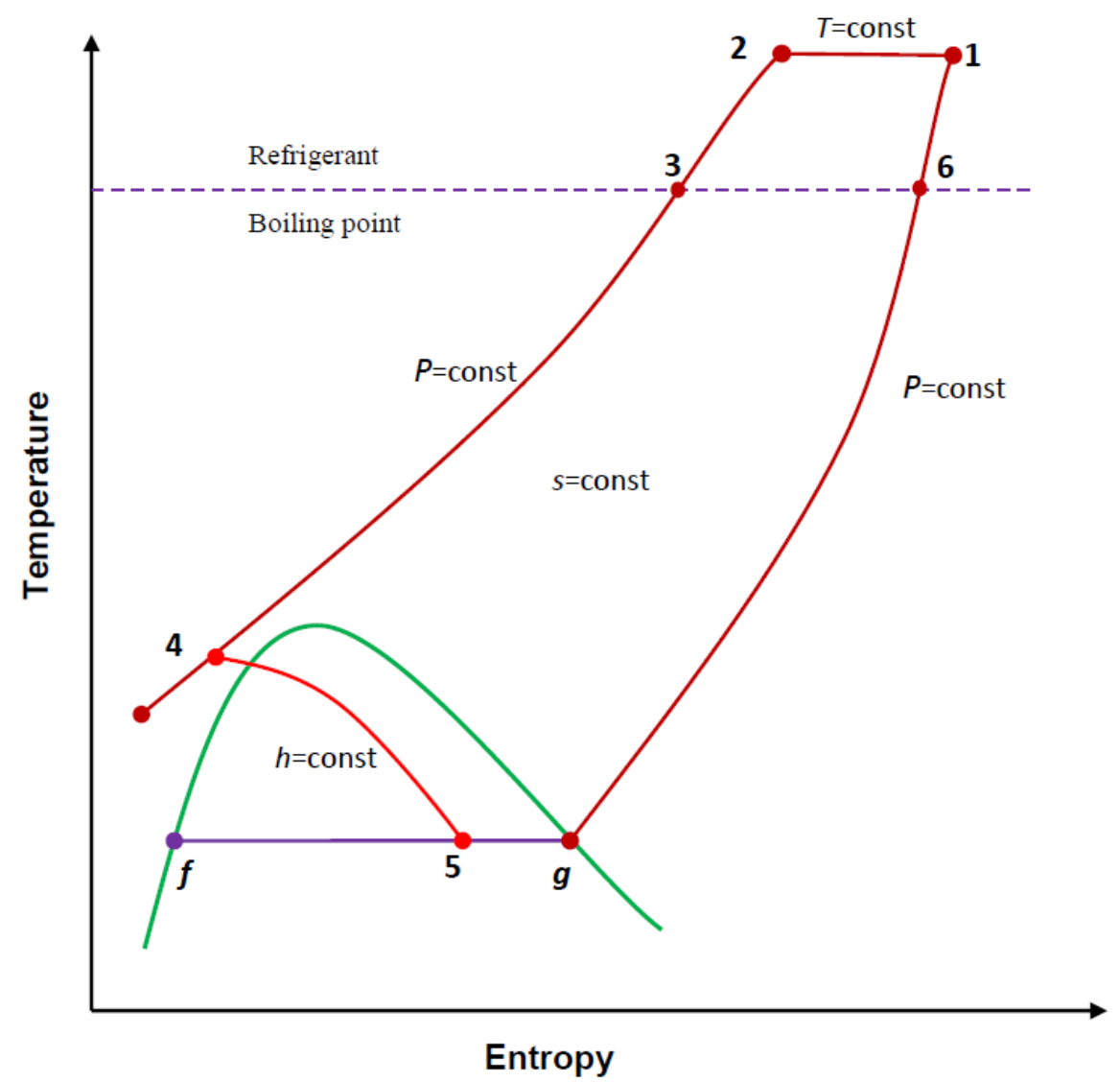

Figure 4. Temperature-entropy (T-s) diagram for a precooled Linde-Hampson cycle.

Liquid yield $y$ for the precooled Linde-Hampson cycle can be expressed as

$$
y=\frac{h_{1}-h_{2}}{h_{1}-h_{f}}+r\left(\frac{h_{a}-h_{b}}{h_{1}-h_{f}}\right)
$$


where $r$ is refrigerant flow rate ratio $\frac{\dot{m}_{r}}{\dot{m}}$ and $h_{\mathrm{a}}$ and $h_{\mathrm{b}}$ are the inlet and outlet of the auxiliary refrigeration cycle's compressor. For suitable value of refrigerant flow-rate ratio, equation (15) can be modified as

$$
y_{\max }=\frac{h_{8}-h_{3}}{h_{8}-h_{f}}
$$

Cycle net liquefaction work input can be written as

$$
w_{\text {im }}=w_{\text {comp }}+\mathrm{w}_{\text {auxilary }}=h_{2}-h_{1}-T_{1}\left(s_{2}-s_{1}\right)-r\left(h_{a}-h_{b}\right)
$$

where $w_{\text {auxilary }}$ is the auxiliary refrigeration cycle's work input.

Performance of the precooled Linde-Hampson cycle using R-134a as an auxiliary refrigerant is investigated for air, nitrogen, oxygen, fluorine, methane, and argon. The temperatures $T_{3}$ and $T_{8}$ are equal to the R-134a's boiling point $\left(-26.1^{\circ} \mathrm{C}\right)$. Auxiliary refrigeration cycle takes freon-134a at 1 atm and compress it to 1.38 atm. Thermodynamic analysis results of the cycle are given in Table 2. Effects of various auxiliary refrigerants on the performance of the cycle are given in Table 3 .

Table 2. Performance parameters of various fluids for a Precooled Linde-Hampson cycle using R-134a as an auxiliary refrigerant.

\begin{tabular}{|l|c|c|c|c|c|c|}
\hline Gas & $y$ & $\begin{array}{c}w_{\text {in }} \\
(\mathrm{kJ} / \mathrm{kg})\end{array}$ & $\begin{array}{c}w_{\text {rev }} \\
(\mathrm{kJ} / \mathrm{kg})\end{array}$ & $\mathrm{COP}_{\text {act }}$ & $\mathrm{COP}_{\text {rev }}$ & $\eta_{\text {II }}$ \\
\hline Air & 0.143 & 3171 & 733.2 & 0,1339 & 0.5791 & 0.2312 \\
\hline Nitrogen & 0.130 & 3552 & 762.1 & 0,1214 & 0.566 & 0.2144 \\
\hline Oxygen & 0.1836 & 2192 & 629.4 & 0,1845 & 0.6426 & 0.2871 \\
\hline Fluorine & 0.1363 & 2506 & 564.5 & 0,1371 & 0.6086 & 0.2252 \\
\hline Argon & 0.1939 & 1664 & 492.6 & 0,1687 & 0.57 & 0.2959 \\
\hline Methane & 0.3358 & 2304 & 1081 & 0,3949 & 0.8421 & 0.4689 \\
\hline
\end{tabular}

Table 3. Performance parameters of Precooled Linde-Hampson cycle with different auxiliary refrigerants.

\begin{tabular}{|l|l|l|l|l|}
\hline Refrigerant & \multicolumn{1}{|c|}{$y$} & \multicolumn{1}{|c|}{$w_{\text {in }}(\mathrm{kJ} / \mathrm{kg})$} & $\mathrm{COP}$ & \multicolumn{1}{c|}{$\eta_{\mathrm{II}}$} \\
\hline Ammonia & 0.1546 & 4138 & 0.1026 & 0.1771 \\
\hline $\mathrm{CO}_{2}$ & 0.2697 & 1934 & 0.2195 & 0.3789 \\
\hline $\mathrm{R} 12$ & 0.1485 & 3171 & 0.1339 & 0.2312 \\
\hline $\mathrm{R} 22$ & 0.1698 & 2853 & 0.1488 & 0.257 \\
\hline $\mathrm{R} 134 \mathrm{a}$ & 0.1430 & 3171 & 0.1339 & 0.2312 \\
\hline
\end{tabular}

\section{Claude cycle}

The expansion process through J-T valve is economically suitable due to its simplicity, but from thermodynamic point of view, it is undesirable because of the irreversibilities. Thermodynamically, expansion valve can be replaced with a turbo expander, as discussed by Kanoglu [17] for LNG cycles. In Claude cycle, expansion engine is used for removing energy from gas stream and producing some work.

The schematic representation of the Claude cycle and the $T-s$ diagram of Claude cycle are given in Figs. 5 and 6, respectively. In Claude cycle, gas stream is compressed to around $40 \mathrm{~atm}$, and then passed through first heat exchanger at state 2 . After first heat exchanger at state 3 , approximately 70-80 percent of the gas diverted from mainstream and expanded through turbo expander. This portion of the gas returns the stream at the entrance of the second heat exchanger in low pressure line. Undiverted gas stream passes through second and third heat exchangers (states 4 and 5) and expand through J-T valve. 


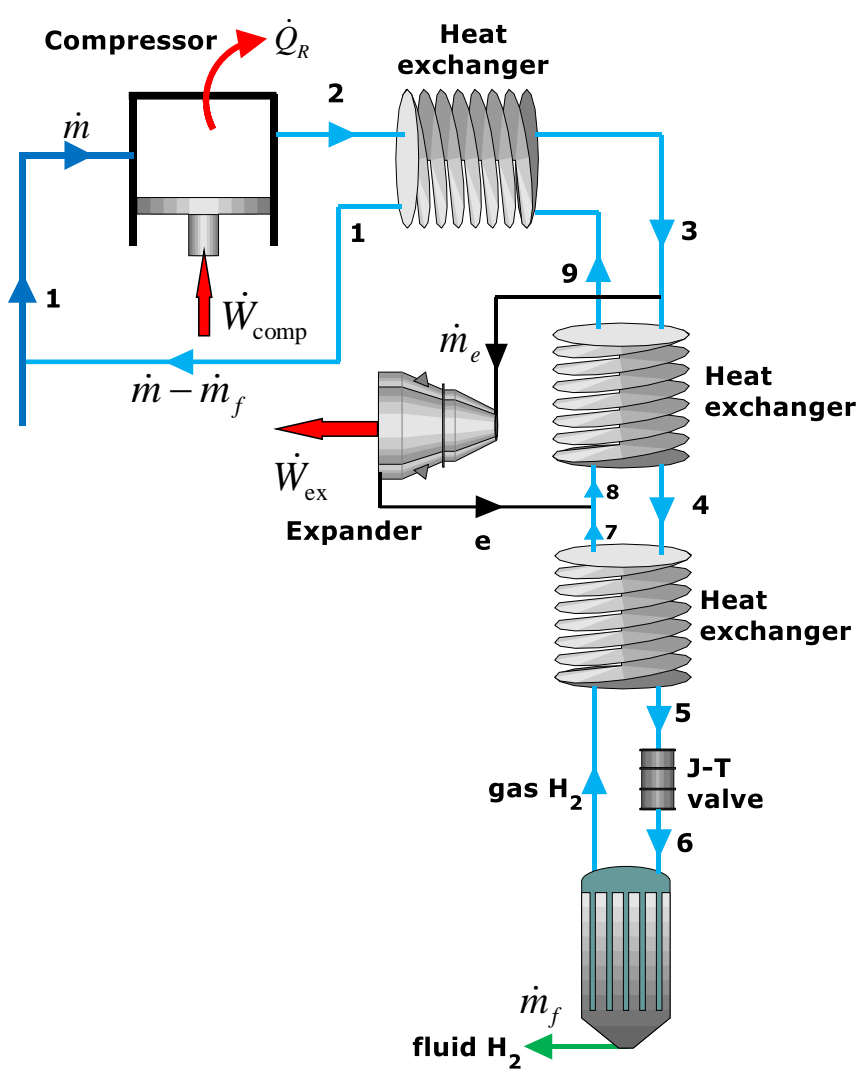

Figure 5. Schematic representation of a Claude Cycle.

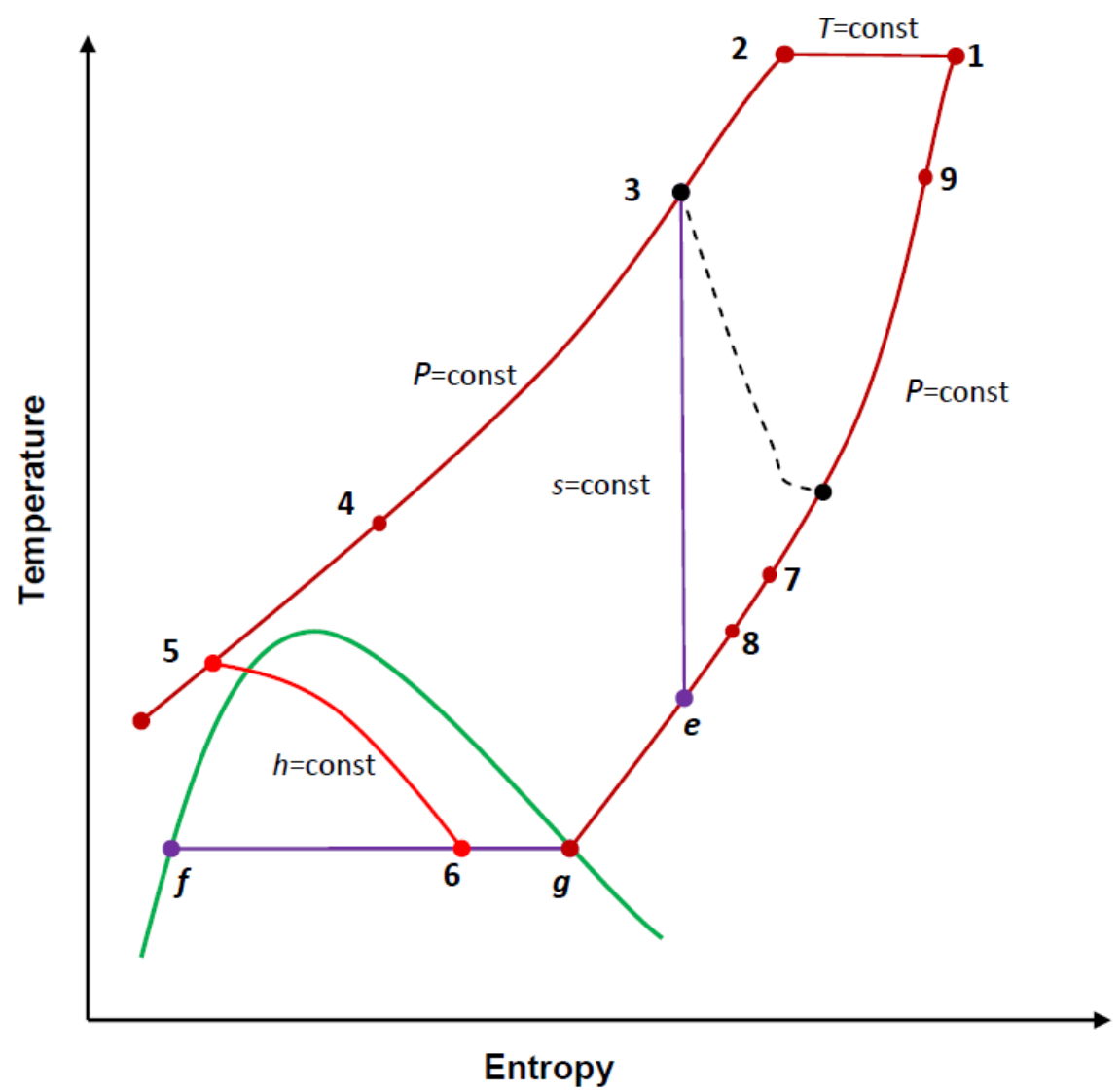

Figure 6. Temperature-entropy (T-s) diagram for a Claude Cycle. 
Refrigeration effect per unit gas for the Claude cycle can be expressed as

$$
q_{l}=h_{1}-h_{2}+z\left(h_{3}-h_{e}\right)
$$

where $z$ is the ratio of gas diverted through the expander to the total flow rate. It can be expressed as

$$
z=\frac{\dot{m}_{e}}{\dot{m}}
$$

The expander can be treated as isentropic and work produced by expander can be written as

$$
\begin{gathered}
s_{3}=s_{e} \\
h_{e}=h_{3}-\eta_{e x}\left(h_{3}-h_{e}^{\prime}\right) \\
w_{e}=h_{3}-h_{e}
\end{gathered}
$$

Liquid yield can be expressed as

$$
y=\frac{h_{1}-h_{2}}{h_{1}-h_{f}}+z\left(\frac{h_{3}-h_{e}}{h_{1}-h_{f}}\right)
$$

Eq. 23 states that, for a constant inlet temperature of the expander $T_{3}$, increasing the expander flow would increase the cooling effect and consequently decrease the inlet temperature of the J-T valve, so more liquid yield is obtained. But when liquefaction increases, the amount of gas return to the cycle is decreased and this reduces the precooling effect. So there is an optimum flow rate diverted through the expander for the cycle.

The work produced by the expander is used in the cycle. Therefore, the net work input is

$$
w_{\text {in }}=w_{\text {comp }}-w_{e}=\left[\left(h_{1}-h_{2}\right)-T_{1}\left(s_{1}-s_{2}\right)\right]-z\left(h_{3}-h_{e}\right)
$$

The Kapitza cycle is a modified version of Claude cycle in which the coldest (third) heat exchanger is removed from the system. First heat exchanger is actually a regenerator which combines purification and precooling. Another notable difference from Claude cycle is that the reciprocation expander is replaced with rotary expander which is more efficient. Kapitza cycle operates at relatively low pressures (7-10 atm). For Kapitza cycle high pressure states 4 and 5, and low pressure states 7 and 8 are identical.

Performance of Claude and Kapitza cycles are investigated for air, nitrogen, oxygen, argon, fluorine and methane. The compressor inlet state is taken $25^{\circ} \mathrm{C}$ and $1 \mathrm{~atm}$ for both cycles but the compressor exit pressure is taken $40 \mathrm{~atm}$ for Claude cycle and $7 \mathrm{~atm}$ for Kapitza cycle. Expanders are assumed to be isentropic. Diverted fraction through the expander $z=0.7$. The results are given at Table 4 and Table 5 for Claude cycle and Kapitza cycle, respectively.

\section{RESULTS AND DISCUSSION}

Gas liquefaction process is a heat rejection process from the gas between inlet state of the compressor and outlet state of the J-T valve. Due to this reason the refrigeration effect per unit mass of the liquefied gas $q_{l}$ are equal for all cycles. Hence, equation 1, 14 and 18 yield same results. The data obtained from Tables 1, 2, 4 and 5 represents performance parameters of the simple Linde-Hampson, precooled Linde-Hampson, Claude and Kapitza cycle for various fluids. The different gases have different performance parameters due to differences in their thermophysical properties. 
Table 4. Performance parameters of various fluids for Claude Cycle.

\begin{tabular}{|l|c|c|c|c|c|c|}
\hline Gas & $y$ & $\begin{array}{c}w_{\text {in }} \\
(\mathrm{kJ} / \mathrm{kg})\end{array}$ & $\begin{array}{c}w_{\text {rev }} \\
(\mathrm{kJ} / \mathrm{kg})\end{array}$ & $\mathrm{COP}_{\text {act }}$ & $\mathrm{COP}_{\text {rev }}$ & $\eta_{\text {II }}$ \\
\hline Air & 0.2488 & 1165 & 733.2 & 0.3644 & 0.5791 & 0.6292 \\
\hline Nitrogen & 0.2493 & 1203 & 762.1 & 0.3585 & 0.566 & 0.6333 \\
\hline Oxygen & 0.2343 & 1122 & 629.4 & 0.3607 & 0.6426 & 0.5613 \\
\hline Fluorine & 0.2330 & 950.6 & 564.5 & 0.3614 & 0.6086 & 0.5938 \\
\hline Argon & 0.2694 & 733.6 & 492.6 & 0.3629 & 0.57 & 0.6366 \\
\hline Methane & 0.2594 & 1955 & 1081 & 0.4655 & 0.8421 & 0.5527 \\
\hline
\end{tabular}

Table 5. Performance parameters of various fluids for Kapitza Cycle.

\begin{tabular}{|l|c|c|c|c|c|c|}
\hline Gas & $y$ & $\begin{array}{c}w_{\text {in }} \\
\left(\mathrm{kJ} \mathrm{kg}^{-1}\right)\end{array}$ & $\begin{array}{c}w_{\text {rev }} \\
\left(\mathrm{kJ} \mathrm{kg}^{-1}\right)\end{array}$ & $\mathrm{COP}_{\text {act }}$ & $\mathrm{COP}_{\text {rev }}$ & $\eta_{\text {II }}$ \\
\hline Air & 0.1628 & 949.2 & 733.2 & 0.4473 & 0.5791 & 0.7724 \\
\hline Nitrogen & 0.1585 & 1055 & 762.1 & 0.4090 & 0.566 & 0.7226 \\
\hline Oxygen & 0.1546 & 907.2 & 629.4 & 0.3607 & 0.4459 & 0.6938 \\
\hline Fluorine & 0.1536 & 769.5 & 564.5 & 0.4465 & 0.6086 & 0.7336 \\
\hline Argon & 0.1623 & 694.5 & 492.6 & 0.4043 & 0.57 & 0.7093 \\
\hline Methane & 0.1429 & 1959 & 1081 & 0.4647 & 0.8421 & 0.5518 \\
\hline
\end{tabular}

The high liquid yield is related with the temperature at the inlet of the Joule-Thompson valve. Precooled Linde-Hampson cycle use auxiliary refrigeration cycle to lower the temperature at the inlet of the valve but have high work input because of auxiliary refrigeration cycle. Claude and Kapitza systems use expansion engine to make pre-cooling effect. As Tables 3 and 4 show, expansion engine help reduce work requirement in the cycle.

Table 1 and Table 2 represent performance parameters of the simple Linde-Hampson cycles and precooled Linde-Hampson cycle. It's clear from the results that simple Linde-Hampson cycle has the lowest efficiency among all liquefaction cycles. By adding auxiliary refrigeration cycle to the simple Linde-Hampson cycle second law efficiency of the cycle increase by about $70 \%$ and work consumption decrease by about $40 \%$.

Table 3 represents effects of different refrigerants used in auxiliary refrigeration cycle on the performance of Precooled Linde-Hampson cycle. Performance of the auxiliary refrigeration cycle and boiling temperature of the auxiliary refrigerant directly affects the overall performance of the cycle. $\mathrm{CO}_{2}$ has the lowest boiling temperature $\left(-78.4^{\circ} \mathrm{C}\right)$ and yield best results among selected auxiliary refrigerants.

Table 4 and 5 represent performance of the expansion engine cycles: Claude and Kapitza cycles. These cycles use expansion engine besides Joule-Thompson valve. Expansion engine provides some refrigeration effect. These cycles have lower work consumption and higher liquid yield. Kapitza cycle operates at lower pressures and provides about $20 \%$ better performance than Claude cycle.

Effect of gas inlet temperature on the liquid yield is shown in Fig. 7 for different cycles. For lower inlet temperatures, greater fractions of gas can be liquefied. This effect is significant in simple Linde-Hampson, precooled Linde-Hampson, and Claude cycle but rather insignificant for Kapitza cycle.

Figs. 8 and 9 show effect of gas inlet temperature on the net work consumptions and second law efficiencies for the liquefaction cycles. As the inlet temperature increases, net work input increases and the second-law efficiency decreases. Net work input for simple Linde-Hampson cycle is the highest and second-law efficiency is the lowest because of low liquid yield. Kapitza and Claude cycles have a better performance than Linde-Hampson cycles. Kapitza and Claude cycles have close work input values. 


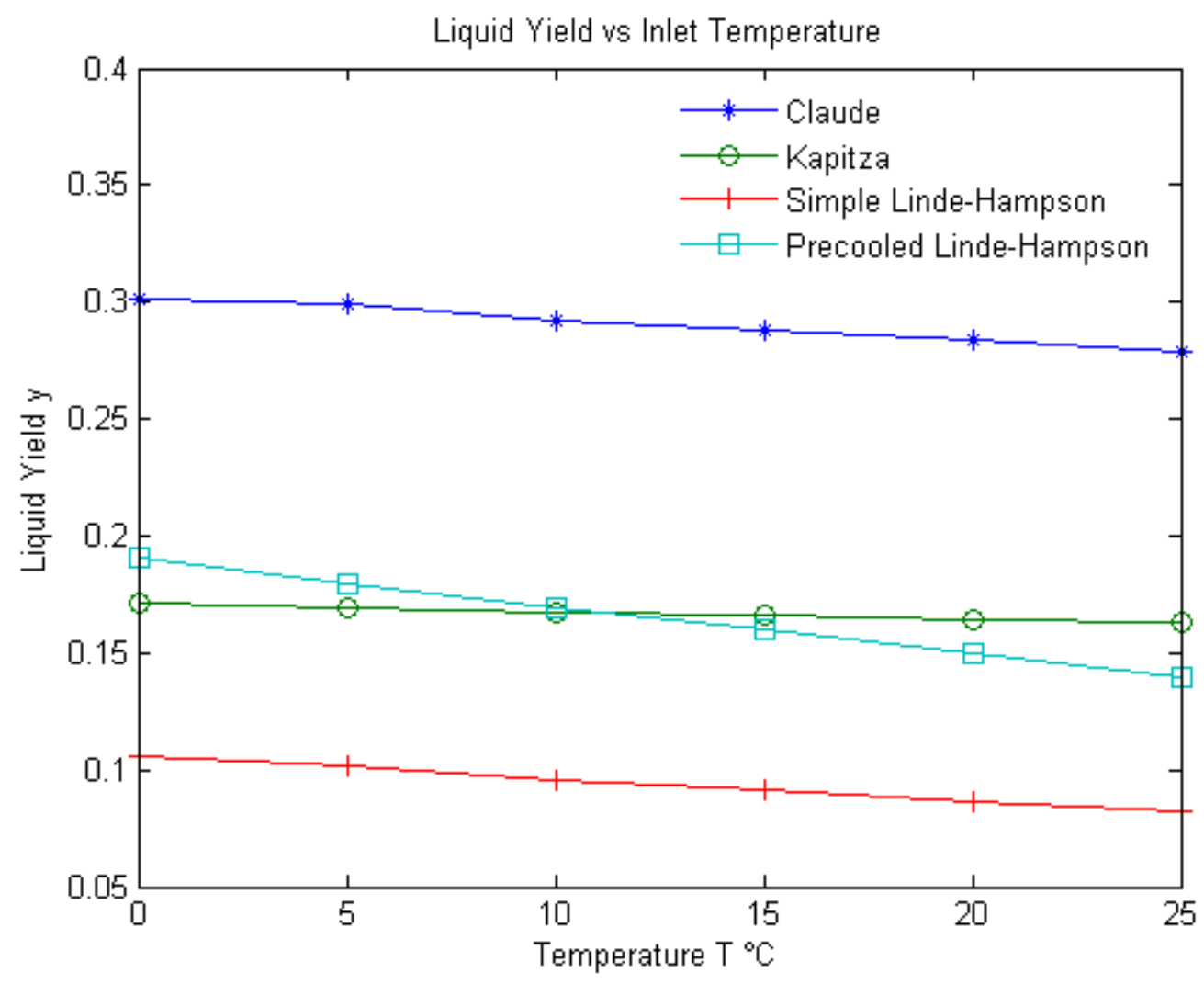

Figure 7. Liquid fraction with respect to the gas inlet temperature.

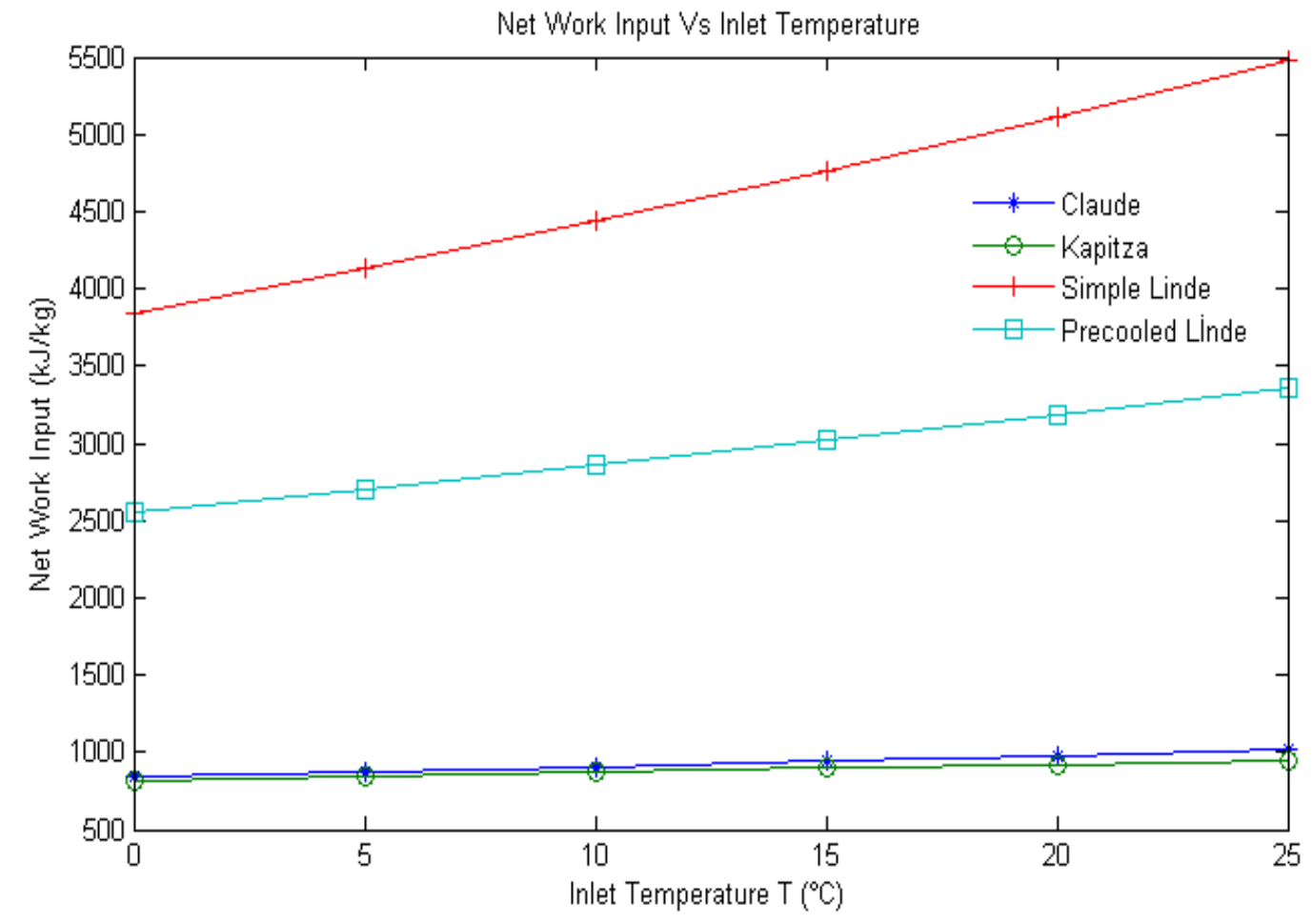

Figure 8. Cycles liquefaction work input with respect to the gas inlet temperature. 
Cycle Efficiencies ws Inlet Temperatures

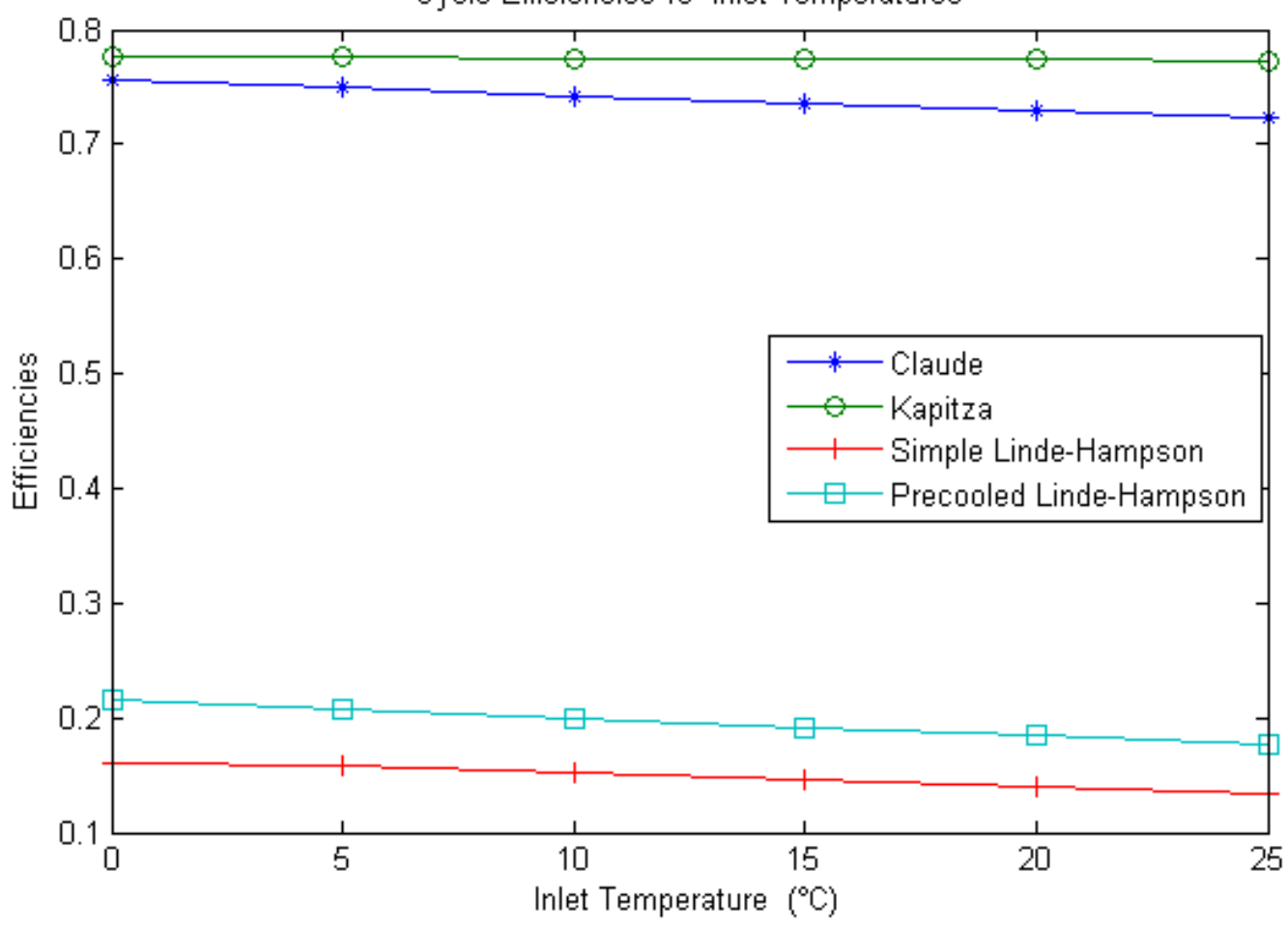

Figure 9. Second law efficiencies of the cycles with respect to the gas inlet temperature.

Table 6. Comparison of the liquefaction systems using air as the working fluid for each cycle.

\begin{tabular}{|c|c|c|c|c|c|}
\hline Gas & $\begin{array}{ll} & \text { Inlet } \\
\text { pressure } & P_{1} \\
\text { (atm) } & \end{array}$ & $y$ & $\begin{array}{c}w_{\text {in }} \\
(\mathrm{kJ} / \mathrm{kg})\end{array}$ & $\mathrm{COP}_{\text {act }}$ & $\eta_{\mathrm{II}}$ \\
\hline $\begin{array}{l}\text { Simple Linde- } \\
\text { Hampson }\end{array}$ & 200 & 0.08228 & 5485 & 0.07741 & 0.1337 \\
\hline $\begin{array}{c}\text { Precooled } \\
\text { Linde-Hampson }\end{array}$ & 200 & 0.1423 & 2118 & 0.1265 & 0.2184 \\
\hline Claude & 40 & 0.2488 & 1165 & 0.3607 & 0.6292 \\
\hline Kapitza & 7 & 0.1628 & 949.2 & 0.4473 & 0.7724 \\
\hline
\end{tabular}

\section{CONCLUDING REMARKS}

The cycles with J-T systems have high work inputs and corresponding low efficiencies but have a simple setup which is desirable. Expansion engine systems have higher efficiencies and lower work inputs but have complex setup. Table 6 gives performance comparison of the Simple Linde-Hampson, Precooled LindeHampson, Claude and Kapitza cycles for air. The work inputs for these liquefaction cycles are 5485, 2118, 1165, and $949 \mathrm{~kJ} \mathrm{~kg}^{-1}$, respectively. Claude cycle has the best liquid yield and Kapitza cycle has the best second law efficiency under given operating conditions.

The following conclusion may be drawn from the thermodynamic performance analysis of the cycles for different gases:

- $\quad$ Simple Linde-Hampson cycle and precooled Linde-Hampson cycle have simple setup but they have low efficiencies.

- Expansion engine cycles are much more efficient than J-T expansion cycles since the power output generated by expander is used to help compression of the gas. 
- $\quad$ Refrigerant used to precool liquefied gas in the auxiliary refrigeration cycle of precooled LindeHampson cycle directly affects the performance of the cycle.

- $\quad$ Mass fraction diverted to the expander in Claude and Kapitza cycles is directly proportional to the refrigeration effect produced by the expander. By increasing the mass fraction diverted to the expander more cooling and more liquid yield can be obtained. But the amount of returning gas decrease and which decreases precooling effect in the heat exchangers. So optimum mass fraction diverted to the expander should be selected. This value usually varies between 0.6 and 0.8 .

- Methods to resolve the challenges of efficient liquefaction include proposing completely new configurations and efficient gas liquefaction cycles coupled with improved efficiencies of the main cycle components such as compressors, expanders, and heat exchangers.

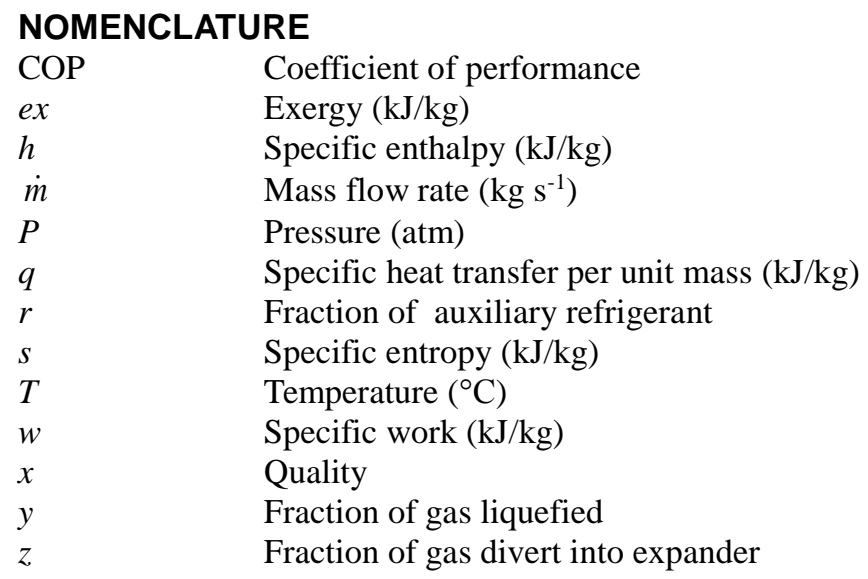

\section{Greek symbols}

$\varepsilon \quad$ Effectiveness of the heat exchanger

$\eta \quad$ Efficiency

\section{Subscripts}

$\begin{array}{ll}\text { act } & \text { Actual } \\ \text { comp } & \text { Compressor } \\ \mathrm{e} & \text { Expander exit } \\ \mathrm{ex} & \text { Expander } \\ f & \text { Fluid } \\ g & \text { Gas } \\ \text { gen } & \text { Generation } \\ \text { rev } & \text { Reversible }\end{array}$

\section{REFERENCES}

[1] Kanoglu, M. (2002). Exergy analysis of multistage cascade refrigeration cycle used for natural gas liquefaction. International Journal of Energy Research, 26(8), 763-774.

[2] Krasae-in, S., Stang, J. H., \& Neksa, P. (2010). Development of large-scale hydrogen liquefaction processes from 1898 to 2009. International Journal of Hydrogen Energy, 35(10), 4524-4533.

[3] Flynn, T. (2004). Cryogenic Engineering, revised and expanded. CRC Press.

[4] Thomas, R. J., Ghosh, P., \& Chowdhury, K. (2011). Exergy analysis of helium liquefaction systems based on modified Claude cycle with two-expanders. Cryogenics, 51(6), 287-294.

[5] Atrey, M. D. (1998). Thermodynamic analysis of Collins helium liquefaction cycle. Cryogenics, 38(12), 1199-1206.

[6] Wang, M., Khalilpour, R., \& Abbas, A. (2014). Thermodynamic and economic optimization of LNG mixed refrigerant processes. Energy Conversion and Management, 88, 947-961.

[7] Mehrpooya, M., \& Ansarinasab, H. (2015). Exergoeconomic evaluation of single mixed refrigerant natural gas liquefaction processes. Energy Conversion and Management, 99, 400-413. 
[8] Bisht, V. S. Thermodynamic Analysis of Kapitza Cycle based on Nitrogen Liquefaction. IOSR Journal of Engineering (IOSRJEN). Vol. 04, Issue 05 (May. 2014), ||V6|| PP 38-44.

[9] Barron, R. F. (1999). Cryogenic Heat Transfer (Vol. 1). Philadelphia, PA: Taylor \& Francis.

[10] Timmerhaus, K. D., \& Flynn, T. M. (1989). Properties of solids. In Cryogenic Process Engineering (pp. 39-102). Springer US.

[11] Maytal, B. Z. (2006). Maximizing production rates of the Linde-Hampson machine. Cryogenics, 46(1), 49-54.

[12] Nandi, T. K., \& Sarangi, S. (1993). Performance and optimization of hydrogen liquefaction cycles. International Journal of Hydrogen Energy, 18(2), 131-139.

[13] Hilal, M. A. (1979). Optimization of helium refrigerators and liquefiers for large superconducting systems. Cryogenics, 19(7), 415-420.

[14] Kanoglu, M., Dincer, I., \& Rosen, M. A. (2008). Performance analysis of gas liquefaction cycles. International Journal of Energy Research, 32(1), 35-43.

[15] Rashidi M.M., Aghagoli A., Raoofi R. (2017). Thermodynamic analysis of the ejector refrigeration cycle using the artificial neural network. Energy 129, 201- 215.

[16] Habibzadeh A., Rashidi M.M., Galanis N. (2013). Analysis of a combined power and ejector-refrigeration cycle using low temperature heat. Energy Conversion and Management 65, 381- 391.

[17] Kanoğlu, M. (2001). Cryogenic turbine efficiencies. Exergy, An International Journal, 1(3), 202-208. 